\title{
EFEK ANTIOKSIDAN FRAKSI ETIL ASETAT MINUMAN SINOM CAMPURAN JERUK NIPIS DAN MADU (curcuma domestica val-tamarindus indica L.) TERHADAP GULA DARAH TIKUS PUTIH SPRAQUE DAWLEY DIABETES MELITUS
}

\author{
N. K. Wiradnyani ${ }^{1 *}$, I M. M. Arimathea ${ }^{2}$ \\ ${ }^{1}$ Program S1 Ilmu Gizi, Universitas Dhyana Pura, Badung, Bali, Indonesia \\ ${ }^{2}$ Program Studi Bioteknologi, Universitas Dhyana Pura, Badung, Bali, Indonesia \\ *e-mail: ani_mw@yahoo.com
}

\begin{abstract}
ABSTRAK
Minuman sinom yang dicampur jeruk nipis dan madu terbuat dari rimpang kunyit dan daun asam muda yang ditambahkan air jeruk nipis dan madu. Tujuan penelitian adalah untuk menentukan efek senyawa antioksidan fraksi etil asetat minuman sinom campuran jeruk nipis dan madu (SCJM) berbagai dosis terhadap gula darah puasa tikus putih spraque dawley (SD) diabetes melitus. Penelitian eksperimental menggunakan RAK, analisis ANOVA dengan uji lanjut BNT ini terdiri dari dua tahap yaitu : 1) uji kapasitas antioksidan berbagai pelarut (SCJM) menghasilkan 29691,1 $\mu \mathrm{g}$ AAEAC/g bahan yaitu angka tertinggi fraksi etil asetat dari n-heksana, khloroform dan air. Tahap ke-2 fraksi etil asetat dari SCJM di uji lanjut secara invivo ke tikus putih SD diabetes melitus dengan perlakuan berbagai dosis yaitu : kontrol (-) tikus normal 50, 100, 150, $200 \mathrm{mg} / \mathrm{dl}$ BB, kontrol (+) tikus diabetes. Hasil penelitian efek senyawa antioksidan SCJM fraksi etil asetat berbagai dosis berpengaruh nyata $(\mathrm{p}<0,01)$ pada penurunan gula darah puasa(GDP) tikus putih SD diabetes melitus, dosis yang dapat menurunkan GDP terendah berdasarkan uji statistik adalah $150 \mathrm{mg} / \mathrm{kg}$ BB tikus yiatu 168,4 mg/dl dari perlakuan dosis yang lain.
\end{abstract}

Kata Kunci: etilasetat, gula darah, antioksidan, sinom

\begin{abstract}
Sinom drinks mixed with lime and honey are made from rhizome of turmeric and young tamarind leaves which are added with lime juice and honey. The aim of the study was to determine the effect of antioxidant compounds of ethyl acetate on sinom drinks mixed with lime juice and honey (SCJM) various doses on fasting blood sugar spraque dawley (SD) white rats diabetes mellitus. Experimental research using RAK, ANOVA analysis with further BNT testing consisted of two stages: 1) test the antioxidant capacity of various solvents of SCJM yielding $29691.1 \mu \mathrm{g}$ AAEAC / g ingredients namely the highest number of ethyl acetate fractions of $\mathrm{n}$ hexane, chloroform, and water. Phase 2 Ethyl acetate fraction of SCJM was further tested in vivo to SD white rats with diabetes mellitus with various doses, namely: control (-) normal mice, 50, 100, 150, $200 \mathrm{mg} / \mathrm{dl} \mathrm{BW}$, control (+) of diabetic rats. The results of the study of the effect of the antioxidant compound SCJM ethyl acetate fraction of various doses significantly affected $(p<0.01)$ in decreasing fasting blood sugar (GDP) white SD diabetes mellitus rats, a dose that can reduce the lowest GDP based on statistical tests is $150 \mathrm{mg} / \mathrm{kg} \mathrm{BW}$ of rats, $168.4 \mathrm{mg} / \mathrm{dl}$ from other doses.
\end{abstract}

Keywords: ethylacetate, blood sugar, antioxidant, sinom

\section{PENDAHULUAN}

Kapasitas antioksidan minuman sinom (MS) pada fraksi air yaitu 199,100 $\mu$ g AAEAC (Ascorbic Acid Equivalent Antioksidan Capacity) /gr bahan diketahui memiliki kapasitas antioksidan yang paling tinggi diantara fraksi n-heksana $(42,800 \mu \mathrm{g}$ AAEAC/gr bahan), kloroform $(94,200 \mu \mathrm{g}$ AAEAC/gr bahan), etil asetat $(66,600 \mu \mathrm{g}$ AAEAC/gr bahan) (Wiradnyani, 2018) dan teruji dengan metode GCMS, diduga mengandung senyawa tumeron $(49,84 \%)$, artumeron $(21,32 \%)$, curlon $(27,25 \%)$ dan 9 oktadekanoat $(69,43 \%)$ (Wiradnyani, 2014). Fraksi etil asetat, khloroform dan n- heksana mengandung senyawa yang diduga seperti tumeron, artumeron dan curlon memiliki prosentase relatif lebih kecil dari fraksi air (Wiradnyani, 2014). Minuman sinom sudah banyak dirasakan oleh sebagaian besar masyarakat untuk menyembuhkan berbagai 
penyakit degenerative khususnya penyakit diabetes melitus dan dishmoria. Namun dalam penggunaanya biasanya ditambahkan air jeruk nipis dan madu. Penambahan air jeruk nipis dan madu memberikan aroma yang lebih segar dan harum, dapat juga mengurangi rasa pahit dari rasa kunyit, menambah nutrisi secara alami, selain dapat menghilangkan jerawat (Mumpuni, 2010). Penentuan kapasitas antioksidan minuman sinom campuran jeruk nipis dan madu SCJM fraksi etil asetat secara kuantitatif pada penelitian ini bertujuan untuk mendapatkan dosis yang dapat menurunkan gula darah puasa terendah.

\section{BAHAN DAN METODE}

\section{Bahan}

Bahan utama yang digunakan dalam penelitian ini terdiri atas bahan baku dan bahan kimia. Bahan baku yaitu rimpang kunyit yang diperoleh dari pasar tradisional Badung, Denpasar, Bali, daun asam yang masih muda dari pucuk daun sampai helai daun ke-tujuh dari daerah Buduk, Mengwi, Badung, Bali, air jeruk nipis, dan madu hutan dari daerah Sumba. Bahan kimia yang digunakan terdiri atas pelarut etil asetat, khloroform, n-heksana (PA merek Emsure Acs 215), kertas saring (Whatman no.1), asam askorbat, $\mathrm{H}_{2} \mathrm{SO}_{4}$, DPPH, methanol, Nicotinic acid, B2 vitamin powder, acetone $\mathrm{NH}_{4} \mathrm{OH}$, Indikator, Silika gel GF254 (Merck), 1gr Aloksan dosis $50 \mathrm{mg} / \mathrm{dl}$ BB tikus, 40 tikus putih SD dari Balai Veteriner Farmako Surabaya, aquades, air demineralisasi, formalin, asam sitrat, natrium sitrat, dan pakan tikus standar, buffer.

Alat
$\begin{aligned} & \text { Peralatan yang digunakan adalah } \\ & \text { timbangan analitik, timbangan biasa, }\end{aligned}$
spektrofotometer merek Shimadzu UV-160,
rotary vacum evaporator, corong pisah,
aluminium foil, Erlenmeyer $250 \mathrm{ml}$, beaker
glass $500 \mathrm{ml}$, tabung reaksi (Pyrex), kain
saring, gelas ukur 100 ml, pipet volume, pipet
tetes, pipet mikro, eksikator, labu takar, vortex,
magnetic stirrer, blood glucose test meter
(merk Nesco), botol gelap, glucose stick (merk
Nesco), 8 buah kandang tikus $35 \times 35 \mathrm{~cm}$, jarum sonde $2 \mathrm{cc}$.

\section{Lokasi Penelitian}

Penelitian ini dilaksanakan pada
Laboratorium Pengolahan Pangan dan
Laboratorium Analisis Pangan Fakultas
Teknologi Pertanian, Universitas Udayana,
Laboratorium Pusat Studi Pangan dan Gizi
Universitas Udayana, Laboratorium Kimia
Forensik Polri Bali, Laboratorium bersama
Univeritas Dhyana Pura.

\section{Cara Kerja}

\section{Uji Kapasitas Antioksidan}

Penelitian tahap ke-1; yaitu uji kapasitas antioksidan dilakukan dengan cara: penyiapan sampel rimpang kunyit yang diperoleh di pasar tradisional Badung, Denpasar, Bali dan daun asam yang masih muda dari pucuk daun sampai helai ketujuh dari daerah Jimbaran, kabupaten Badung, Provinsi Bali. Rimpang kunyit dikupas, ditimbang sebanyak 50 gram, dicuci, dihaluskan menggunakan blender dengan menambahkan $400 \mathrm{ml}$ air selama 3,5 menit, disaring untuk mendapatkan filtrat, kemudian dipanaskan sampai mendidih selama 1 menit. Filtrat yang diperoleh lalu dicampur dengan filtrat daun asam muda yang sudah dicuci, diperoleh dengan cara menimbang seberat 250 gram daun asam muda, ditambahkan $300 \mathrm{ml}$ air, kemudian dipanaskan dengan cara mendidihkan selama 1 menit. Setelah dingin setiap $100 \mathrm{ml}$ ditambahkan 10 gram air jeruk nipis dan madu. Minuman SCJM selanjutnya dimasukan ke dalam botol kaca dan didinginkan sampai tidak ada uap panasnya, selanjutnya siap digunakan untuk pengujian.

Fraksinasi minuman SCJM dengan menggunakan etil asetat, yang dilakukan sebagai berikut: $100 \mathrm{ml}$ minuman SCJM dimasukan ke dalam labu pisah yang telah dikeringkan dalam oven selama 15 menit pada suhu $100^{\circ} \mathrm{C}$, selanjutnya ditambahkan etil asetat $100 \mathrm{ml}$, dikocok $10 \mathrm{kali}$ dan didiamkan selama 30 menit. Fraksi etil asetat dievaporasi dengan suhu $45^{\circ} \mathrm{C}$ dan tekanan $280 \mathrm{mbar}$ 
untuk menghilangkan pelarut. Uji antioksidan fraksi minuman SCJM dilakukan berdasarkan penelitian (Winarsi, 2007) dengan rumus:

$\underline{\text { Konsentrasi }(\mathrm{ppm}) \times \mathrm{Tv} \times \mathrm{Fp} \times 1000.000}$

$$
\text { W sampel (mg) }
$$

Keterangan:

$\mathrm{Tv}=$ total volume (liter),

$\mathrm{Fp}=$ pengeceran,

Konsentrasi $=$ hasil penghitungan kurva standar, AAEAC $=$ Ascorbic Acid Equivalent Antioksidan Capacity.

Penetapan dosis dan persiapan fraksi minuman SCJM adalah: dosis yang diberikan adalah dosis lazim konsumsi suplemen per hari pada manusia yang dikonversi dari manusia ke tikus. Perhitungan pemberian dosis berdasarkan pada "body surface area" (BSA) mengikuti penelitian yang dilakukan oleh Reagan-Shaw et al (2007). Rumus konversi dosis disajikan sebagai berikut :

HED $(\mathrm{mg} / \mathrm{kg})=$ animal dose $(\mathrm{mg} / \mathrm{kg}) \mathrm{X}$ animal $\mathrm{Km} /$ human $\mathrm{Km}$

diasumsikan suplemen antioksidan perhari pada manusia rata-rata sebesar $500 \mathrm{mg} / 60 \mathrm{~kg}$ $\mathrm{BB}$, maka HED (human equivalent dose) $(\mathrm{mg} / \mathrm{kg})=8,3$. Apabila dikonversi ke tikus maka perhitungan menjadi :

$8,3 \mathrm{mg} / \mathrm{kg}=$ animal dose $(\mathrm{mg} / \mathrm{kg} \mathrm{BB}) \times 6 / 37$, animal dose $=8,3 \times 37 / 6,=51,2 \mathrm{mg} / \mathrm{kg} \mathrm{BB}$

Berdasarkan perhitungan di atas, maka dosis yang diberikan untuk tikus bervariasi dari 50, 100, 150 dan $200 \mathrm{mg} / \mathrm{kg}$ BB tikus. Fraksi etil asetat minuman SCJM sudah ditimbang beratnya sesuai dengan dosis yang akan diberikan pada tikus dilarutkan di dalam $2 \mathrm{ml}$ aquades, kemudian dihomogenkan dengan vortek agar tercampur dengan merata. Pemberian fraksi etil asetat SCJM cara ini bertujuan untuk mempermudah pemberian pada tikus putih secara oral yang diberikan sesuai dengan masing-masing dosis fraksi setiap pagi pada jam 07.30 - 08.00 WIB.

\section{Penentuan Dosis}

Penelitian tahap ke-2 menggunakan Rancangan Acak Kelompok (RAK) dilakukan secara bioassay menggunakan 20 ekor tikus putih SD dengan perlakuan dosis pemberian fraksi etil asetat minuman SCJM penelitian tahap ke-1 yang terdiri dari 5 taraf yaitu: tikus kontrol (-) diberikan fraksi etil asetat SCJM 0 $\mathrm{mg} / \mathrm{kg}$ BB atau diberi aquades $2 \mathrm{ml} / \mathrm{ekor}$, tikus kontrol positif (+) tikus diabetes tanpa pemberian SCJM, diberikan secara oral (disonde) fraksi etil asetat SCJM: (K1) dosis $50 \mathrm{mg} / \mathrm{kg}$, (K2) dosis $100 \mathrm{mg} / \mathrm{kg}$, (K3) dosis $150 \mathrm{mg} / \mathrm{kg}$, (K4) dosis $200 \mathrm{mg} / \mathrm{kg}$ BB tikus, masing-masing ditambahkan $2 \mathrm{ml}$ aquades, pemberian satu kali sehari pagi hari. Masingmasing ada 5 kelompok dan 4 ekor tikus sebagai ulangan. Pengukuran kadar gula darah diadakan pada tahap ini, setiap 3 hari sekali dari pengambilan data ke- $0,3,6,9,12,15,18$ dan 21. Pemeriksaan gula darah dilakukan setiap jam 07.00-08.00 WITA, setelah dipuasakan selama 12 jam tetapi tetap diberi minum. Kadar gula darah diukur dengan alat blood glucose test meter Gluco Dr. Selanjutnya di analisis dengan menggunakan Annova $1 \%$, uji lanjut BNT.

Penentuan jumlah ulangan dan sampel: penelitian ini mengunakan 20 unit tikus jantan galur SD berumur dua bulan dengan berat badan 200 sampai dengan 250 gr, dari 20 ekor ini diambil masing-masing empat ekor untuk setiap taraf perlakuan sehingga jumlah ulangan adalah empat kali. Penggunaan jumlah sampel yang lebih besar pada penelitian ini untuk menghindari terjadinya kekurangan sampel sampai pada akhir penelitian yang diduga akibat kematian sampel.

\section{ANALISIS DATA}

Uji kapasitas antioksidan dan rendemen fraksi minuman sinom campuran jeruk nipis dan madu dianalisis dengan menggunakan analisis varian (ANOVA). Apabila terdapat pengaruh yang bermakna (taraf 1\%) maka analisis dilanjutkan dengan uji beda rerata antar perlakuan dengan uji perbandingan berganda Uji Beda Nyata terkecil (BNT). 


\section{HASIL DAN PEMBAHASAN}

Senyawa yang diduga terkandung dalam minuman SCJM setelah difraksinasi dengan menggunakan berbagai pelarut telah diketahui bahwa kapasitas antioksidan tertinggi adalah minuman SCJM yang menggunakan pelarut etil asetat. Minuman SCJM oleh GCMS terdeteksi 18 komponen senyawa penyusun seperti disajikan pada Gambar 1.

Senyawa mayor ini memiliki aktivitas biologis sebagai antikanker dan antidiabetes (Wiradnyani, 2019). Hasil GCMS dapat dilihat pada Tabel 1.

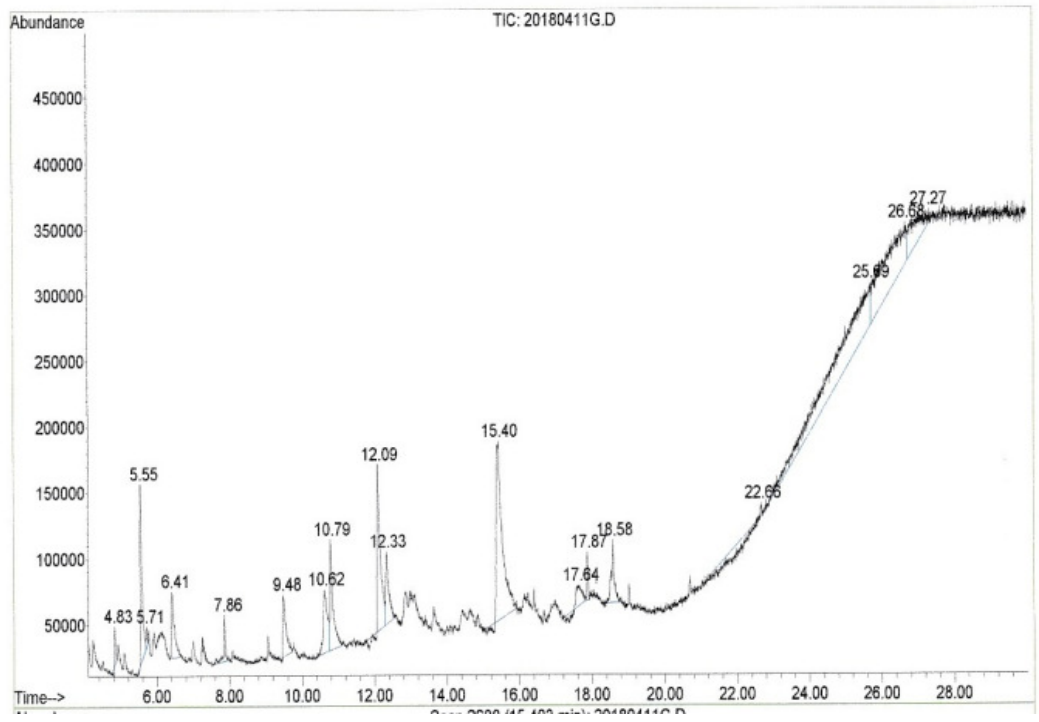

Gambar 1. Kromatogram GCMS Senyawa yang Terdapat pada Fraksi Etil Asetat Minuman SCJM

Tabel 1. Identifikasi dengan GCMS Fraksi Etil Asetat Minuman SCJM

\begin{tabular}{ccclc}
\hline No & RT & Area (\%) & \multicolumn{1}{c}{ Nama Senyawa } & Qual \\
\hline 1 & 4.83 & 0,56 & 1-Butanamine,N-methyl-N-nitro & 53 \\
2 & 5.54 & 4,95 & L-Sorbose & 40 \\
3 & 5.71 & 0,32 & 3-Furaldehyde & 38 \\
4 & 6.41 & 2,95 & Propylcarbamate & 23 \\
5 & 7.86 & 1,20 & 2,4 Dihydroxy-2,5-dimethy1-3(2H)-furan-3-one & 53 \\
6 & 9.48 & 2,73 & 4,5-Diamino-2-hydroxpyrimidine & 53 \\
7 & 10.62 & 3,88 & Propanal, 2,3-dihydroxy-,(S)- & 25 \\
& & & 4H-Pyran-4-one,2,3-dihydro-3,5-dihydroxyl-6- & 83 \\
8 & 10.79 & 5,04 & methyl- & 87 \\
9 & 12.08 & 7,76 & 5-Hydroxymethylfurfural & 10 \\
10 & 12.33 & 3,28 & 3-Buten-2-one,4-(2-azido-1-hydroxy-2,6,6- & 18 \\
& & & trimethylcyclohexyl) butanoic acid, 3 oxo-,hexyl ester \\
11 & 15.4 & 16,7 & Pivalaldehyde & 58 \\
12 & 17.64 & 0,81 & Epicurzerenone & 27 \\
13 & 17.86 & 1,05 & N,N'-Dimethyl-1,4-butanediamine & 49 \\
14 & 18.58 & 4,03 & Cyclotrisiloxane,hexamethyl & 49 \\
15 & 22,67 & 17,90 & Naphtho\{2,1-\}furan,dodecahydro-6,9a-dimethyl-, \\
& & \multicolumn{4}{c}{ \{3aS-3a.alpha.,5a.alpha.,6.alpha.,9a.beta.,9b.alpha.)\} } \\
16 & 25.69 & 27,31 & 4-(4-Hydroxyphenyl)-4-methyl-2-pentanone & 43 \\
17 & 26.68 & 2,62 & Tumerone & 38 \\
18 & 27.27 & 5,58 & Arsenous acid,tris (trimethylsily1) ester & 49 \\
\hline
\end{tabular}


Uji Kapasitas Antioksidan dimulai dengan penentuan standar asam askorbat atau vitamin $\mathrm{C}$ dalam mereduksi radikal bebas $\operatorname{DPPH}(1,1$ difenil-2-pikrilhidra-zil) $0,1 \mathrm{mM}$ dapat dilihat pada Gambar 2 yaitu kurva kalibrasi asam askorbat standar hubungan kapasitas antioksidan $(\mathrm{mg} / \mathrm{l})$ fraksinasi dengan pelarut etil asetat ekstrak minuman SCJM.

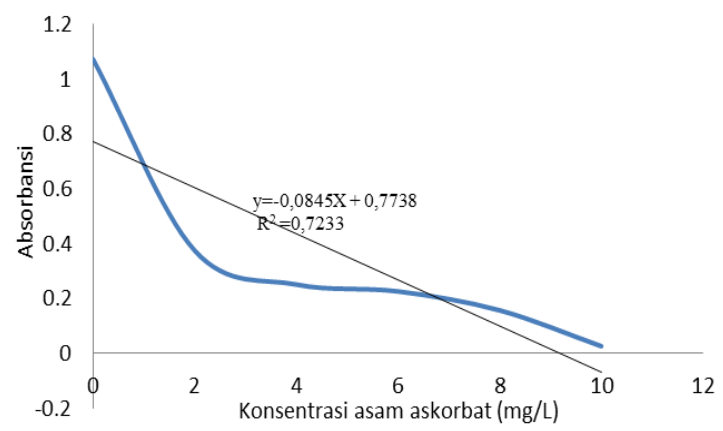

Gambar 2. Kurva Kalibrasi Asam Askorbat Standar

\section{Hasil Kapasitas Antioksidan Rata-Rata Minuman SCJM}

Tabel 2. Hasil Pengujian Kapasitas Antioksidan ( $\mu$ g AAEAC/g bahan) Perlakuan Berbagai Pelarut Minuman SCJM

\begin{tabular}{lc}
\hline \multicolumn{1}{c}{ Pelarut } & $\begin{array}{l}\text { Kapasitas Antioksidan } \\
(\mu \mathrm{g} \text { AAEAC/g bahan })\end{array}$ \\
\hline n-Heksan & $16551.1^{\mathrm{ac}} \pm 4,688$ \\
Cloroform & $23819.1^{\mathrm{bc}} \pm 4,688$ \\
Etil Asetat & $29691.1^{\mathrm{d}} \pm 4,688$ \\
Air & $18089.7^{\mathrm{de}} \pm 4,688$ \\
\hline $\begin{array}{l}\text { Notasi huruf } \\
\text { enunjukkan } \\
\text { (BNT). }\end{array}$ & $\begin{array}{l}\text { yang berbeda dalam kolom yang sama } \\
\text { perbedaan yang signifikan pada p }<0,05\end{array}$
\end{tabular}

Kapasitas antioksidan minuman SCJM hasil fraksi dengan perlakuan berbagai jenis pelarut dari hasil penelitian dicantumkan pada Tabel 2. Besarnya kapasitas antioksidan fraksi etil asetat memiliki nilai tertinggi yaitu 2969,1 $\mu \mathrm{g}$ AAEAC/g bahan, dibandingkan n-heksan (16551,1 $\mu \mathrm{g}$ AAEAC/g), kloroform (23819,1 $\mu \mathrm{g} \quad$ AAEAC/g $) \quad$ dan air $(18089,7 \quad \mu \mathrm{g}$ AAEAC/g).

Hal ini disebabkan oleh kemampuan senyawa bioaktif yang ada di dalam minuman SCJM sangat sesuai dengan sifat-sifat pelarut etil asetat sehingga sifat semi-polar pelarut etil asetat dimiliki juga oleh senyawa bioaktif minuman SCJM yang mampu mengkelat radikal bebas pada DPPH, penelitian ini sesuai dengan analisis senyawa antioksidan fraksi etil asetat daun Libo (Ficus Variegate Blume) yang di teliti oleh Novitasari (2016).

\section{Rata-Rata Gula Darah Puasa (GDP) Tikus Putih SD Diabetes Berbagai Dosis Fraksi Etil Asetat Minuman SCJM}

Berdasarkan uji statistik, analisis keragaman menunjukkan bahwa senyawa antioksidan pada perlakuan berbagai dosis 50 , $100,150,200 \mathrm{mg} / \mathrm{kg}$ BB tikus, fraksi etil asetat minuman SCJM pada tikus SD diabetes melitus berpengaruh nyata $(\mathrm{p}<0,01)$ terhadap GDP tikus.

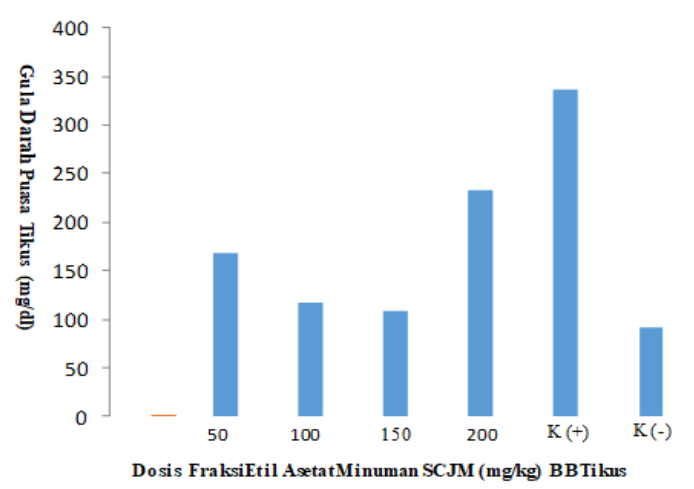

Gambar 3. Grafik rerata berbagai dosis Fraksi Etil Asetat (MSJM) terhadap GDP tikus DM

Gambar 3 menjelaskan bahwa GDP tikus terbaik adalah yang diberikan dosis $150 \mathrm{mg} / \mathrm{kg}$ karena memberikan nilai terendah $(168,4$ $\mathrm{mg} / \mathrm{dl}$ ), berbeda nyata dari perlakuan dosis yang lainya. Glutathione reduktase memperbaiki fungsi mitokondria sangat dibutuhkan untuk membuat flavin mononukleotida (FMN) dan flavin adenine dinukleotida (FAD). Antioksidan seperti ini lebih baik (sinergisme) kemampuanya mengkelat radikal bebas ada pada sel $\beta$ karena induksi Streptotozin (Setyo, 2012).

\section{SIMPULAN DAN SARAN}

\section{Simpulan}

1. Perlakuan berbagai dosis pemberian fraksi minuman SCJM berpengaruh nyata $(\mathrm{p}<0,01)$ terhadap GDP tikus putih SD diabetes melitus 
2. Kapasitas antioksidan tertinggi SCJM berbagai pelarut adalah fraksi etil asetat (29691,1 ( $\mu \mathrm{g}$ AAEAC/g bahan)

3. Dosis terbaik yang dapat menurunkan GDP terendah berdasarkan uji lanjut BNT adalah $150 \mathrm{mg} / \mathrm{kg}$ BB dapat menurunkan GDP $168,4 \mathrm{mg} / \mathrm{dl}$.

4. Fraksi etil asetat minuman SCJM digunakan untuk menurunkan GDP

\section{Saran}

Penelitian ini sebaiknya di lanjutkan melakukan uji penurunan gula darah puasa pada manusia.

\section{UCAPAN TERIMAKASIH}

Penulis mengucapkan terimakasih kepada Kemenristek Dikti yang telah mendanai penelitian ini.

\section{DAFTAR PUSTAKA}

Emiwati, 2007. Efek Konsumsi Minuman Bubuk Kakao Bebas Lemak terhadap Sifat Antioksidan dan Proliferative Limfosit Manusia. Disertasi. Bogor: Institut Pertanian Bogor.

Erwin, E., Etriwati, E., Muttaqin, M., Pangesttiningsih, T.W., Widyarini, S. 2013, Ekspresi Insulin pada Pankreas Mencit (Musculus) yang Diinduksi dengan Streptozotocin Berulang, $J$ Kedokteran Hewan. 7(2): 97-100.

Purbaya, J. R. 2002. Mengenal \& Memanfaatkan Khasiat Madu alami. Bandung: Pionir Jaya.

Kumalaningsih, S. 2006. Antioksidan Alami. Surabaya: Trubus Agrisarana.

Lukita-Atmadja W., Ito, Y., Baker, G.L., McCuskey, R.S. 2002. Effect of curcuminoids as anti-inflammatory agents on the hepatic microvascular response to endotoxin. SHOCK, 17 (5): 399-403.

Mumpuni, Y.A., Wulandari. 2010. Cara Jitu Mengatasi Jerawat, Jogyakarta: Andi.

Novitasari, M. R, Febrina, L., Agustina, R., Rahmadani, A., Rusli, R. 2016. Analisis GCMS Senyawa Aktif Antioksidan Fraksi etil asetat Daun Libo (Ficus variegate Blume), Jurnal Sains dan kesehatan. 1(5): 221- 225.

Razak, A., Djamal, A., Revilla, G. 2013. Artikel Penelitian Uji Daya Hambat Air Perasan Buah Jeruk Nipis (Citrus aurantifolia s.) Terhadap Pertumbuhan Bakteri Staphylococcus Aureus Secara In Vitro, Jurnal Kesehatan Andalas. 2(1): 58 .

Shaw- Reagan, S., Nihal, M., Ahmad, N. 2007. Dose Translation from Animal to Human Studies Revisited. The FASEB Journal. 22: 659-661.

Setyo, P. D. H. 2012. Pengaruh Fraksi Etil Asetat Buah Labu Siam (Sechium edule (Jacq.) SW.) Terhadap Regenerasi Sel $\beta$ Pankreas pada Tikus Diabetes yang Diinduksi Aloksan. .Sekolah Tinggi Ilmu Farmasi Yayasan Pharmasi Semarang .STIFAR. Semarang

Winarsi. 2007. Antioksidan Alami dan Radikal Bebas. Yogyakarta: Kanisius.

Wiradnyani, N. K., Wartini, N. M., Harsojuono, B. A. 2014. Komposisi Senyawa Antioksidan Minuman Sinom (Curcuma domestica Val - Tamarindus Indica L.), Scientific Journal of Food Technology, 1(1):10-23.

Wiradnyani, N. K., 2018. Kapasitas Antioksidan Minuman Sinom. Proceeding Sintesa Undhira, 1(6): 381389. 